Supporting Information

\title{
A Label-Free and Regenerable Aptasensor for Real-Time Detection of Cadmium (II) by Dual Polarization Interferometry
}

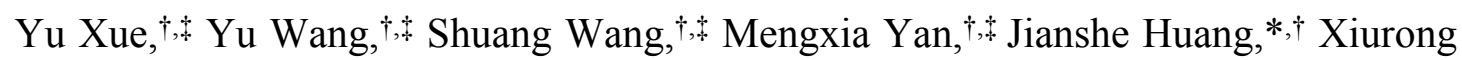
Yang*,†,

$\uparrow$ State Key Laboratory of Electroanalytical Chemistry, Changchun Institute of Applied Chemistry Changchun, Jilin 130022, China

\$ University of Science and Technology of China, Hefei, Anhui 230026, China

*Fax:+86 431 85689278. E-mail: xryang@ciac.ac.cn, huangjs@ciac.ac.cn 
Table S1. Sequences of the DNA oligonucleotides used in this work.

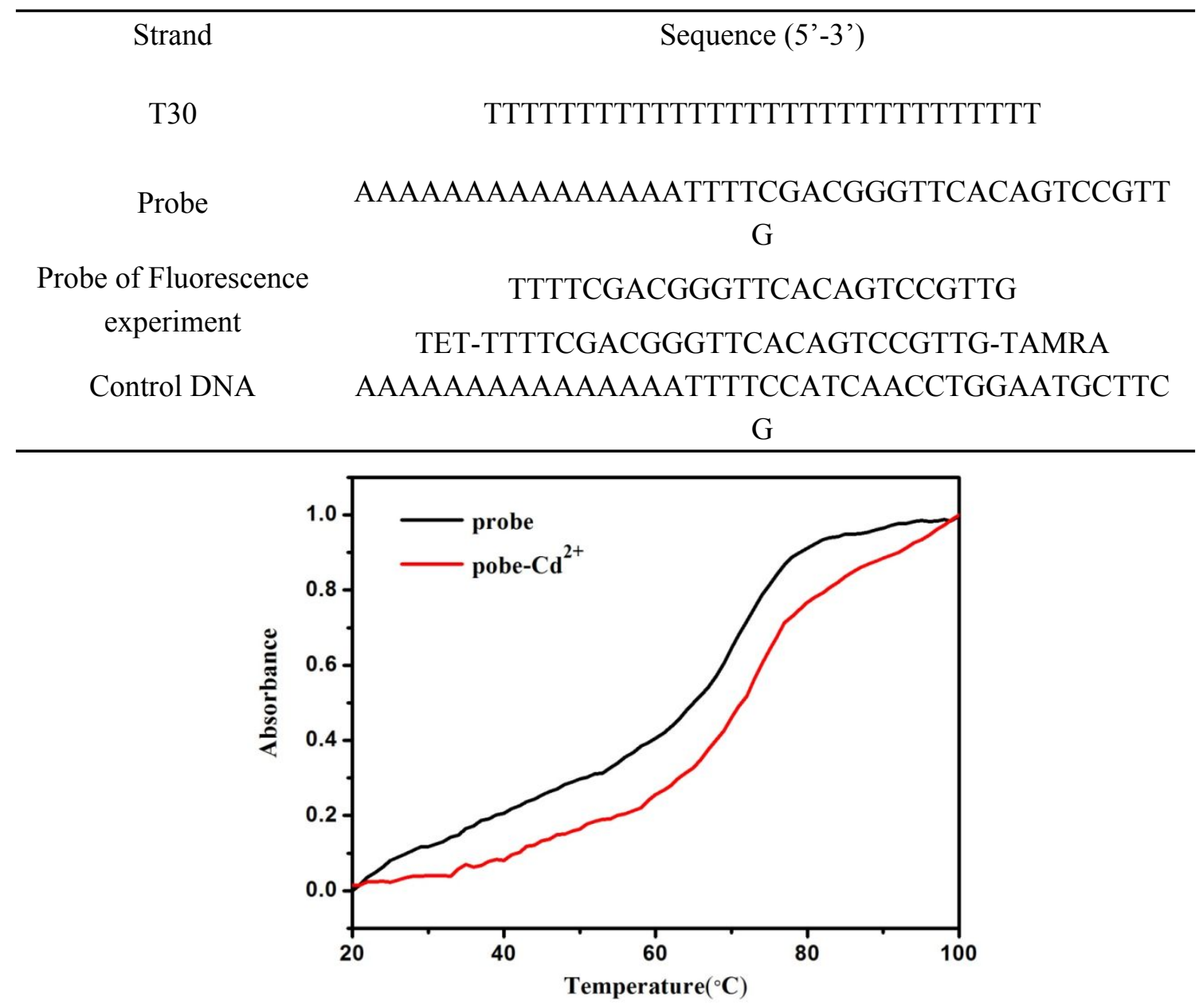

Figure S1. The melting cure of probe with (red line) and without $\mathrm{Cd}^{2+}$ (black line). The concentration of probe and $\mathrm{Cd}^{2+}$ is $1.5 \mu \mathrm{M}$ and $30 \mu \mathrm{M}$ respectively. The temperature range of the melting cure is from $20^{\circ} \mathrm{C}$ to $100{ }^{\circ} \mathrm{C}$ and the increase rate of temperature is $1{ }^{\circ} \mathrm{C} / \mathrm{min}$. The absorbance values represent the absorption of probe at $260 \mathrm{~nm}$. 

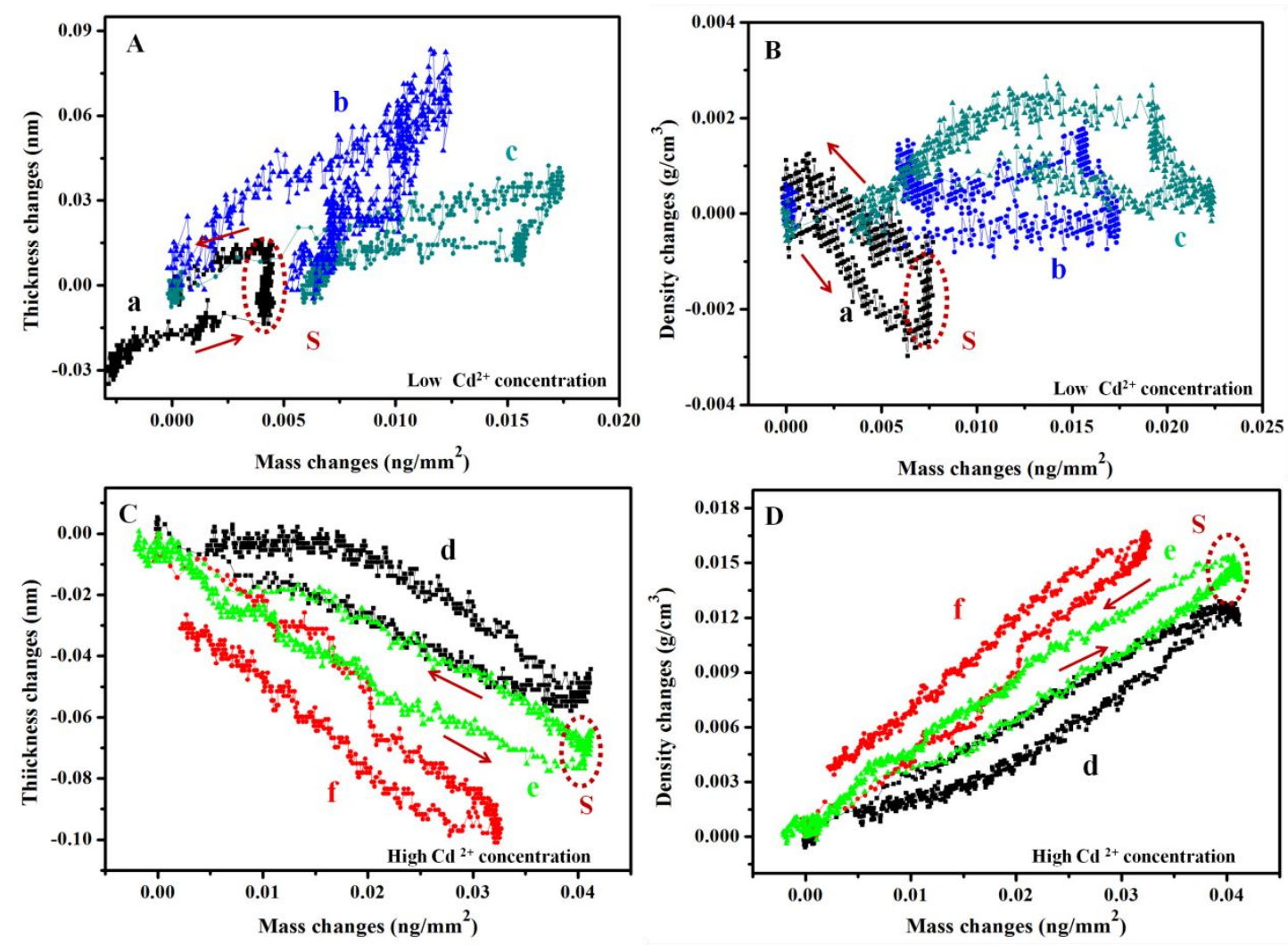

Figure S2. Whole dynamic process of interaction between $\mathrm{Cd}^{2+}$ and probe. Layer thickness $(\mathrm{A}, \mathrm{C})$ and density $(\mathrm{B}, \mathrm{D})$ of probe as a function of the respective mass loading are studied under low $(\mathrm{A}, \mathrm{B})$ and high $(\mathrm{C}, \mathrm{D}) \mathrm{Cd}^{2+}$ concentration. $\mathrm{Cd}^{2+}$ concentrations of a-f are 0.018 , $0.18,0.36,1.82,3.60,7.28 \mathrm{mg} / \mathrm{L}$. The short arrows present the start and finish of interaction process. The wine-red loops $\mathrm{S}$ display the turning region. 

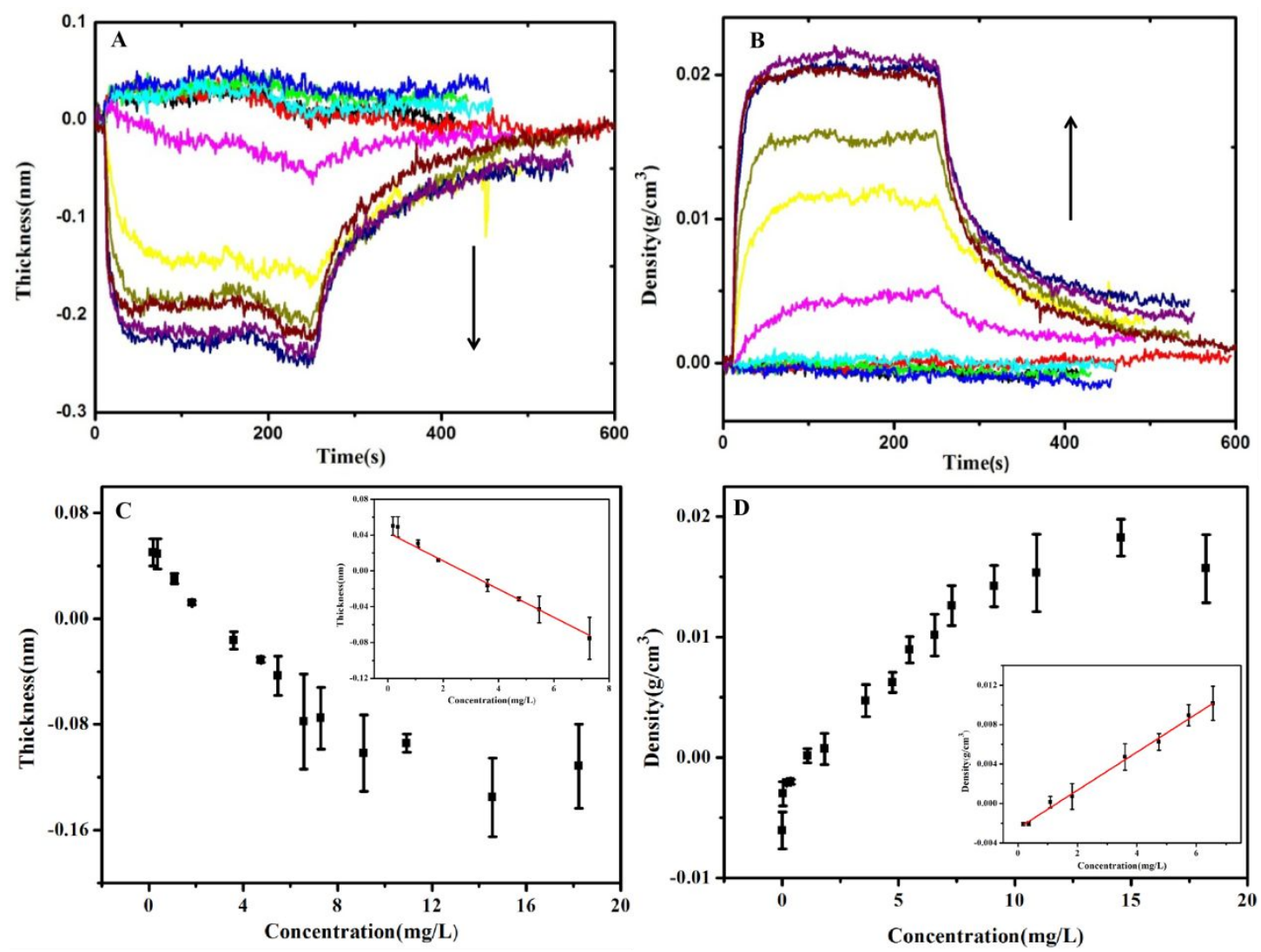

Figure S3. The real-time thickness and density change trends (A, B) and linearity range (C, D) of probe layer with adding different concentrations of $\mathrm{Cd}^{2+}$. The arrows in (A) and (B) show the increase of $\mathrm{Cd}^{2+}$ concentration from 0.0036 to $29.15 \mathrm{mg} / \mathrm{L}$, the plot in (C) and (D) at concentrations of $\mathrm{Cd}^{2+}$ between 0.0036 and $18.22 \mathrm{mg} / \mathrm{L}$. The insets show expanded linear region ranging from 0.0036 to $7.28 \mathrm{mg} / \mathrm{L}$. The linear equation could be fitted as Thickness $(\mathrm{nm})=-0.00574 \mathrm{c}+0.04271\left(\mathrm{R}^{2}=0.986\right)$ and Density $\left(\mathrm{g} / \mathrm{cm}^{3}\right)=0.000715 \mathrm{c}-0.00253\left(\mathrm{R}^{2}=\right.$ 0.986) respectively, where $\mathrm{Cd}^{2+}$ concentration $\mathrm{c}$ has units of milligram per liter. The limits of detection $(3 \sigma)$ are $10.85 \mu \mathrm{g} / \mathrm{L}$ for thickness calibration and $7.57 \mu \mathrm{g} / \mathrm{L}$ for density calibration. The arrow bars present the standard deviation of three measurements. 


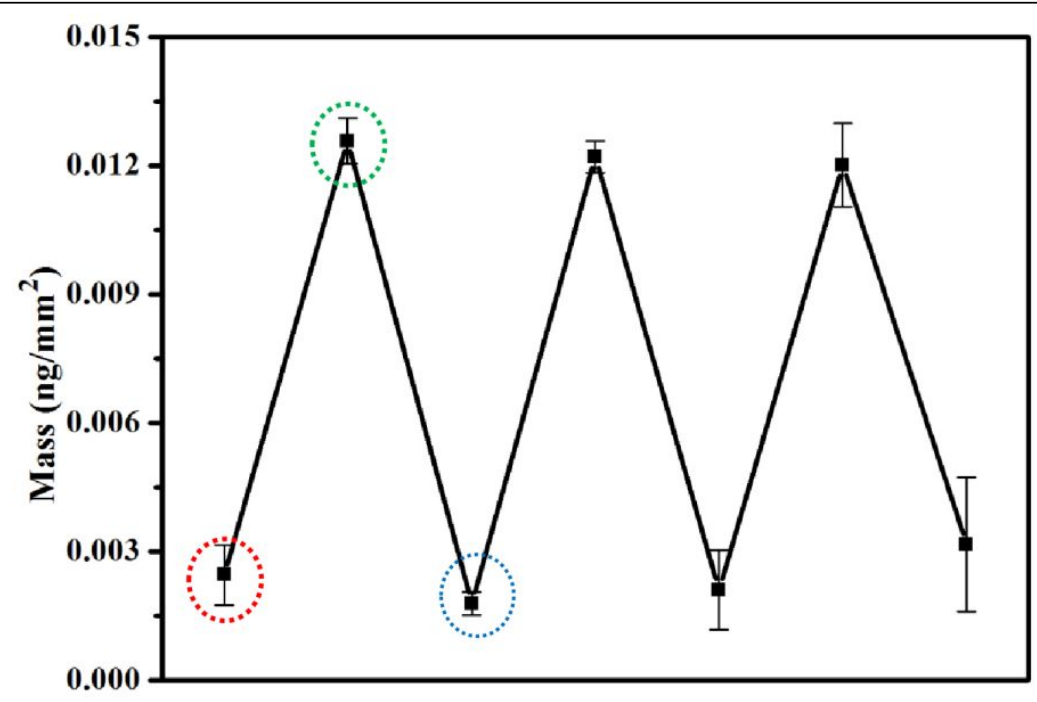

Figure S4. The regeneration plot of aptasensor. The red, green and blue dotted line represent the initial sate without $\mathrm{Cd}^{2+}$, the injection of $0.36 \mathrm{mg} / \mathrm{L} \mathrm{Cd}^{2+}$ for $1 \mathrm{~min}$ and the reintroduction of buffer solution for $10 \mathrm{~min}$, respectively. And the plot exhibits three cycles, the arrow bars present the standard deviation of three measurements.
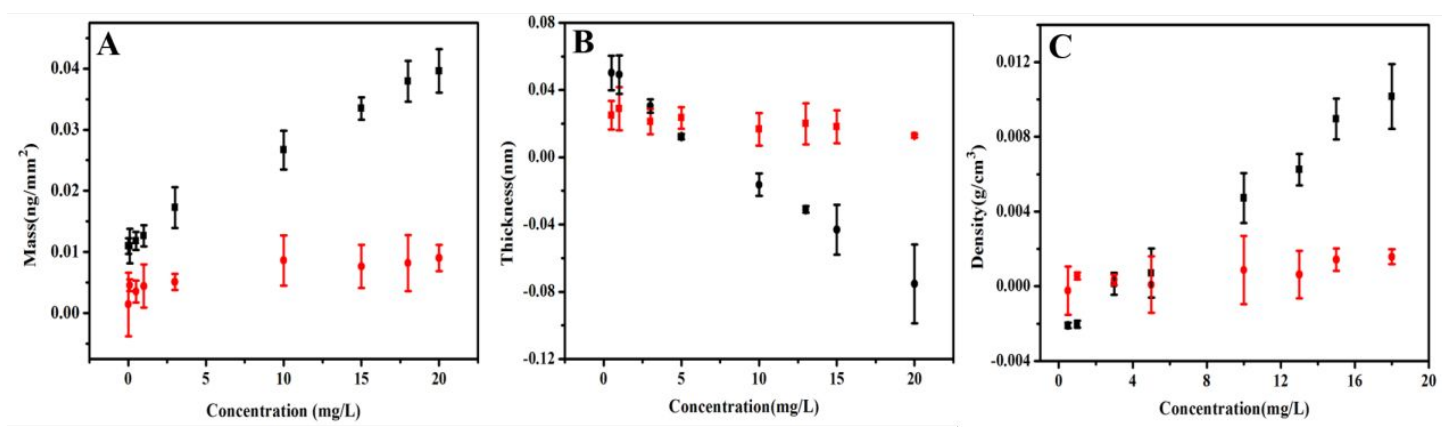

Figure S5. Mass (A), thickness (B) and density (C) value changes of probe layer (black lines) and control DNA layer (red lines) after adding different concentrations of $\mathrm{Cd}^{2+}$ in the range from 0.0036 to $7.28 \mathrm{mg} / \mathrm{L}$. 
A

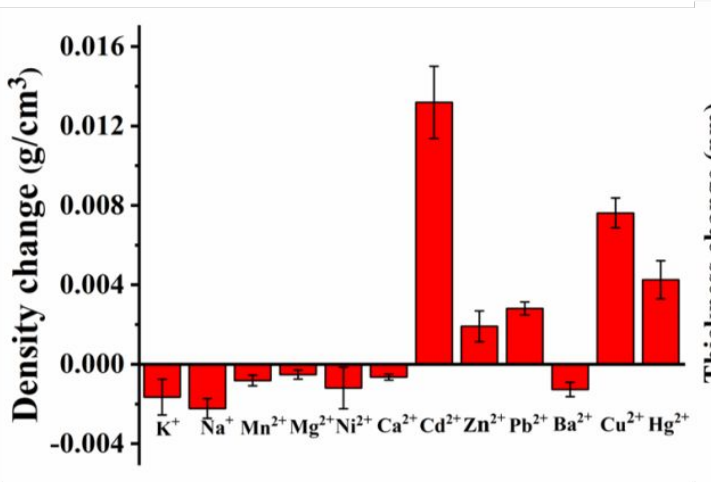

B

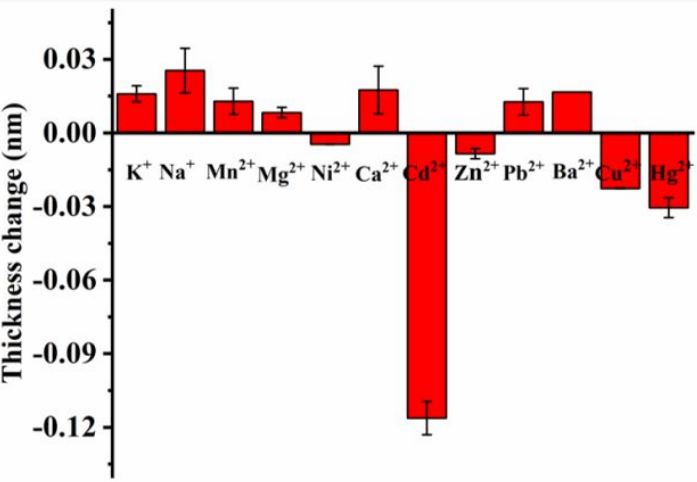

Figure S6. Selectivity of $\mathrm{Cd}^{2+}$-aptasensor. Histograms (A) and (B) present density and thickness changes, respectively. The concentration of all metal ions is $7.28 \mathrm{mg} / \mathrm{L}$.

In order to further illustrate the conformation change of DNA aptamer depending on the concentrations of $\mathrm{Cd}^{2+}$, the two fluorescence experiments were carried out. The fluorescence spectra are displayed in Figure S7 and Figure S8. In one method, the fluorescent dyes SYBR Green I, which is a nucleic acid fluorescent dye binding with double-standed DNA (dsDNA) and oligonucleotide specifically, ${ }^{1}$ was selected to stain the DNA aptamer. As shown in Figure S7, the fluorescence intensity of SYBR Green I was greatly enhanced after adding the native (nonthermally denatured) DNA probe, suggested that the shot hairpin structure existed intrinsically in this DNA probe (which is expected according to the sequence of aptamer). After the thermal denaturation, the fluorescent intensity declined due to the partial denaturation of the DNA probe to form ssDNA. When the low concentration of $\mathrm{Cd}^{2+}(2 \mu \mathrm{M})$ was added to the thermally denatured probe, the change of fluorescent intensity is negligible compared with the native probe. This result indicated that the low concentration of $\mathrm{Cd}^{2+}$ could not induce the formation of dsDNA, and they probably bound with the phosphate group on the DNA backbone. However, when high concentration of $\mathrm{Cd}^{2+}$ ions $(40 \mu \mathrm{M})$ were added to the thermally denatured probe, the fluorescence intensity of SYBR Green I was enhanced obviously, indicating that the dsDNA proportion in DNA probe was increased. That is to say, the high concentration of $\mathrm{Cd}^{2+}$ ions can induce the formation of hairpin structure.

In another experiment, the fluorescent dyes labeled aptamer was designed, where TET at 5' acted as fluorescence donor and TAMRA at 3' acted as fluorescence acceptor. When the 514 $\mathrm{nm}$ excitation light is applied, the fluorescent emission wavelength of TET located in the 
range of $540-550 \mathrm{~nm}$, which overlapped with the excitation wavelength of TAMRA (547 $\mathrm{nm}$ ). Therefore, a distance dependent fluorescence resonance energy transfer (FRET) system was constructed and was used to verify the conformation change of probe. As shown in Figure S8, after addition of $\mathrm{Cd}^{2+}$ the fluorescence intensity of TET at $540 \mathrm{~nm}$ was decreased dramatically, accompanied by the enhanced fluorescence intensity of TAMRA at $580 \mathrm{~nm}$, which confirmed that the distance of TET and TAMRA was shortened and the FRET between them was happened. The results also confirmed that $\mathrm{Cd}^{2+}$ could bind to the bases of probe by coordination interaction, thus promoting the conformation transfer of aptamer from single stand to double stand.

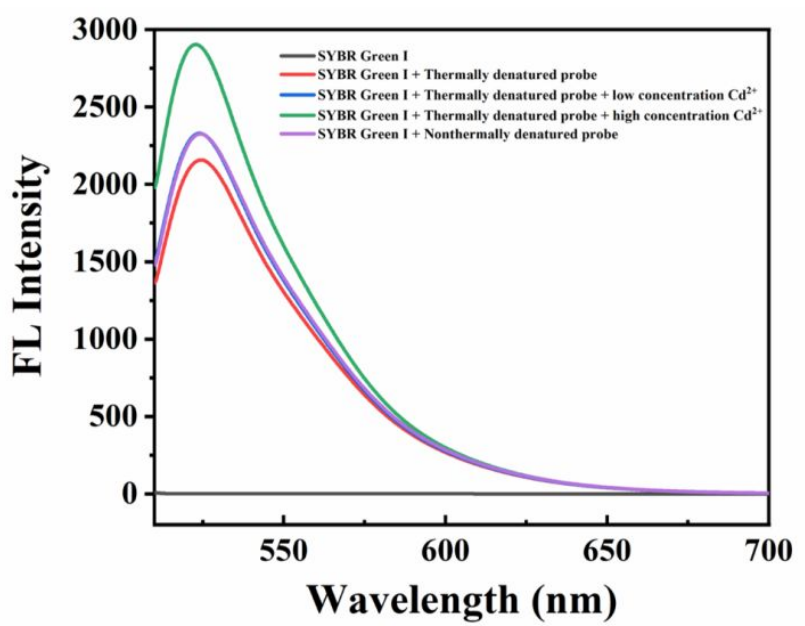

Figure S7. Fluorescence spectra of SYBR Green I at different conditions. The concentration of probe is $2 \mu \mathrm{M}$, the low and high concentrations of $\mathrm{Cd}^{2+}$ is $2 \mu \mathrm{M}$ and $40 \mu \mathrm{M}$, respectively. The concentration of SYBR Green I, diluted by buffer solution (10 mM Tris- $\mathrm{HCl}, 150 \mathrm{mM}$ $\mathrm{NaCl}, \mathrm{pH} 7.0$ ) from $10000 \times$, is $4 \times$. Thermally denatured method is same with the experiment section in manuscript. The excitation wavelength of SYBR Green I is $497 \mathrm{~nm}$, the excitation and emission slit are both $10 \mathrm{~nm}$.

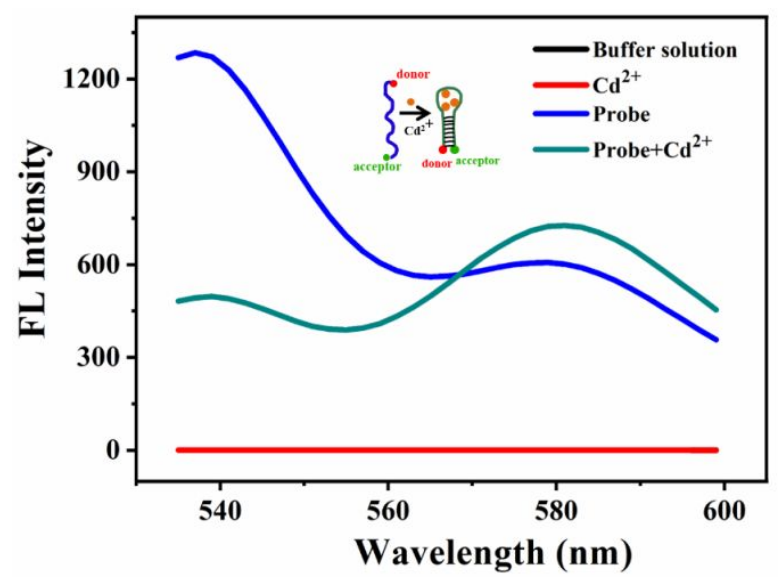

Figure S8. Fluorescence spectra characterize the interaction mechanism between probe and $\mathrm{Cd}^{2+}$. The concentration of probe and $\mathrm{Cd}^{2+}$ are $2 \mu \mathrm{M}$ and $32.4 \mu \mathrm{M}$ respectively. Thermally -7 - 
denatured method of probe is same with the experiment section in manuscript and the excitation wavelength of TET is $514 \mathrm{~nm}$, the excitation and emission slit are both $10 \mathrm{~nm}$.
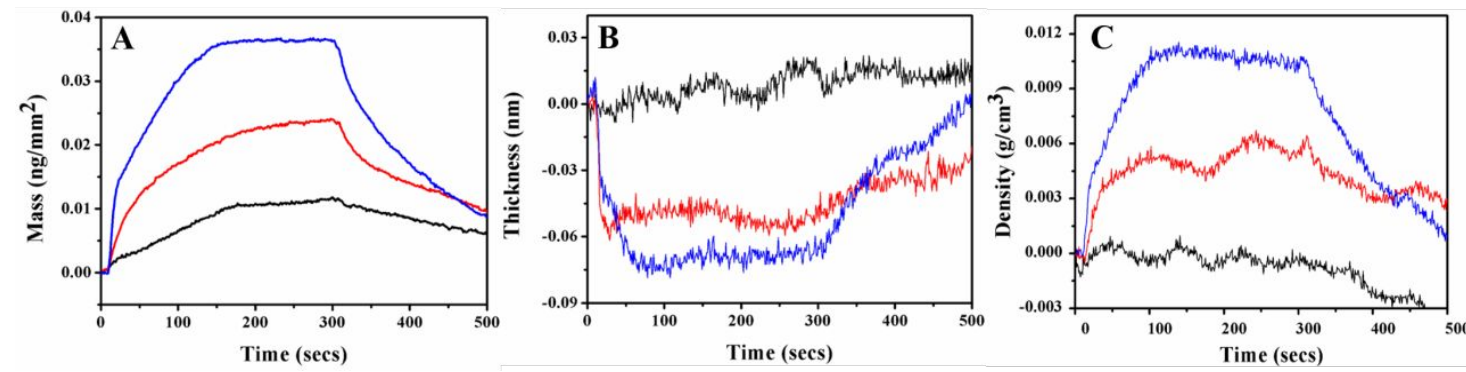

Figure S9. The real-time mass (A), thickness (B) and density (C) change of the aptasensor to the tapping water samples with adding different concentrations of $\mathrm{Cd}^{2+}$. The black, red and blue dash line represented the real samples adding $3.24 \mu \mathrm{M}, 32.41 \mu \mathrm{M}$ and $64.82 \mu \mathrm{M} \mathrm{Cd}^{2+}$.

Table S2. Detection of $\mathrm{Cd}^{2+}$ in tapping water samples.

\begin{tabular}{cccccccccc}
\hline & \multicolumn{3}{c}{ Mass } & \multicolumn{3}{c}{ Thickness } & \multicolumn{3}{c}{ Density } \\
\hline Add $(\boldsymbol{\mu M})$ & 3.24 & 32.41 & 64.82 & 3.24 & 32.41 & 64.82 & 3.24 & 32.41 & 64.82 \\
Measured $(\boldsymbol{\mu M})$ & 4.31 & 33.80 & 67.73 & 3.79 & 32.98 & 63.98 & 3.89 & 32.14 & 64.93 \\
Recovery (\%) & 133 & 104.3 & 104.5 & 117 & 101.8 & 98.7 & 120 & 99 & 100 \\
RSD (n=3, \%) & 3.85 & 3.49 & 3.67 & 4.10 & 9.37 & 3.41 & 13.93 & 5.23 & 0.26 \\
\hline
\end{tabular}

\section{Reference}

(1) Skeidsvoll, J.; Ueland, P. M.; Anal. Biochem. 1995, 231, 359-365. 